Available Online : https://proceeding.researchsynergypress.com/index.php/cset/index

RSF Conference Series: Engineering and Technology

ISSN 2809-6843 (Online) | 2809-6878 (Print)

Volume 1 Number 1 (2021): 368-377

\title{
Tailings Dam Conceptual Design with Geomechanical Material Properties Approach to Determine Safety Criteria
}

\author{
Oktarian Wisnu Lusantono' ${ }^{1}$, Aldin Ardian², Istifari Husna Rekinagara ${ }^{3}$ \\ 1) Faculty of Mineral and Technology, Univeritas Pembangunan Nasional "Veteran" Yogyakarta \\ 2) PT Studio Mineral Batubara, Mining Consultant, Yogyakarta
}

\begin{abstract}
Geotechnical conditions as one of the conditions considered in the design and planning of tailings dams are strongly influenced by material conditions. The material condition is a parameter that will always be taken into account with stability. The material condition can be defined as a behavior that is based on the physical and mechanical properties of the material. By understanding the behavior of materials in a tailings dam construction, the risk of geotechnical failure can be controlled and minimized. This research was intended to study and investigate the behavior of material based on the geomechanically properties of the material used in a model. Generally, to determine the geomechanically properties of a material, several tests, both in-situ and laboratory tests, are required. Laboratory testing uses international standards such as ISRM (International Society of Rock Mechanics) and ASTM (American Standard Testing Materials). The research methodology used is descriptive quantitative research method. The studied parameter in this research is the geomechanically properties that influence the material on its conceptual design in terms of safety criteria (safety factor and probability of landslides) on the tailings dam embankment.
\end{abstract}

Keywords: Conceptual Design, Geomechanically Properties, Tailings Dam.

This is an open access article under the CC-BY-NC license

\section{INTRODUCTION}

Mining is identical to sustainable and targeted environmental management. In order to actualize this environmental management, mining companies generally have the infrastructure to manage water and mine waste before it is distributed into water bodies. Therefore, the existence of a tailings dam is a crucial thing for mining companies.

The following definition is taken from [1], tailings are materials resulting from mineral or coal processing that generally have a fine grain size. Commonly tailings are pumped as a slurry (a mixture of solids and liquids) into a storage area known as a tailings dam. In general, the design and planning of tailings dam construction were carried out by applying engineering principles by considering the following risks: flooding, seismic activity conditions, geological conditions, geotechnical conditions, surface water conditions, and groundwater. A mining industry usually undertakes the construction of a tailings dam in stages by considering operational capacity.

Geotechnical conditions as one of the conditions considered in the design and planning of tailings dams are strongly influenced by material conditions. The condition of the material is a parameter that will always be taken into account in relation to stability. The material condition can be defined as a behavior that is based on the material's physical and mechanical properties [2]. By understanding the material behavior in a tailings dam construction, the risk of geotechnical failure can be controlled and minimized. The aim of this research is to analyze and evaluate material behavior using a model based on the material's geomechanical characteristics.

\section{RESEARCH METHOD}

The used research methods in this study are quantitative and descriptive research with the following stages: data acquisition, data processing, literature study, and data analysis. Data acquisition is the process of collecting data that will be used to conduct research. Data that have been taken are rock samples for the tailings pile material formation. Rock samples were taken using the full-coring method 
in Tanjung Enim, South Sumatra. The sampling was carried out by PT Studio Mineral Batubara as the donor in this study.

The next stage in data acquisition is laboratory testing. The data from laboratory test result will be processed using distribution fitting methods and descriptive statics. The conceptual modeling of the tailings dam will be conducted out utilizing PT Studio Mineral Batubara's Slide 2 and RS2 software, which has been officially licensed from Rocscience ${ }^{\mathrm{TM}}$.

A literature study was conducted in order to strengthen the data analysis. The literature that will be used is literature related to the research topic i.e., geotechnical, mining, and civil engineering. The literature used will be in the form of textbooks, reports, guidelines, and journals from the previous 1020 years.

Data analysis was carried out after going through the stages of data acquisition, data processing, and literature study. Data analysis is a triangulation process that requires a scientific approach based on the results of the literature and the results of data processing. The analysis will focus on explaining the modeling results and the results of laboratory data processing.

\section{Slope Stability Analysis}

The Factor of Safety (FoS) calculation can be done using an approach in two ways: Limit Equilibrium Method and numerical methods (Finite Element Method). The illustration of the forces acting on the boundary equilibrium method is shown in Figure 1. The slope is divided into numerous slices and the pressures on each slide are described. Calculations are also carried out repeatedly (iteratively) to obtain the smallest FoS value and determine the critical slip surface.

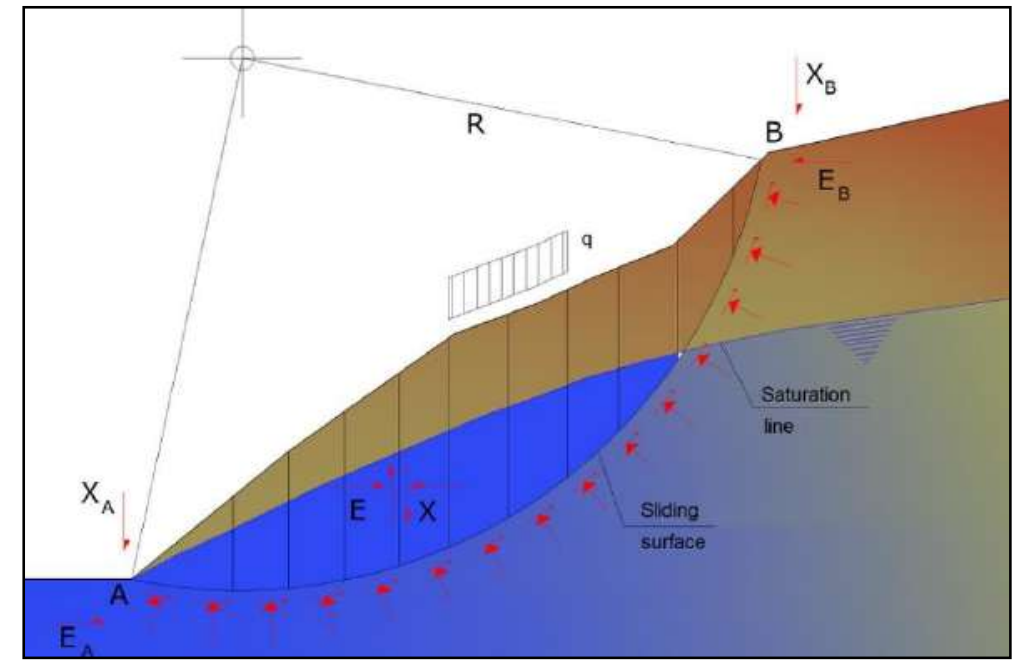

Figure 1. Limit Element Model Illustration

A numerical method is a method that can be used to solve complex and fast problems. Numerical methods commonly used in slope stability analysis are finite element methods, finite difference methods, and discrete element methods [3]. This study used the finite element method. It aims to determine the material behavior and the displacement criteria that will occur from the modeling results to the model.

Finite element method used in this study is a 2-dimensional element method using a plane stress and strain approach. It means that at every node there will be a displacement that can cause strain on an element. Therefore, the stress value for each element can be estimated based on the strain value that occurs in the element. The illustration of the finite element method on the slope is shown in Figure 2. 


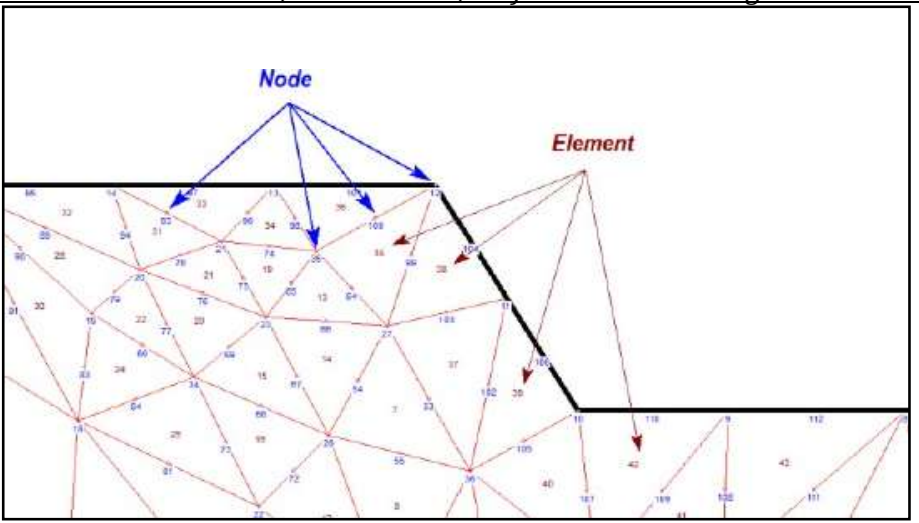

Figure 2. Finite Element Model Illustration

\section{Geotechnical Analysis of Tailings Dam}

Geotechnical analysis of the tailings dam area has been carried out by several previous researchers [4, $5,6]$.In the book written by Terzaghi [4], sub-chapter hydrodynamic conditions of the soil said that soft materials such as soil can undergo a phase change (solid-liquid) in a certain time. This phase change can cause the material's strength criteria to change significantly. In the book written by Das [6], in the subchapter of slope stability analysis, said that the slope stability expressed in the Factor of Safety is closely related to the shear strength of a material. The book by Kramer [5], in the seismic response sub-chapter, said that seismic activity such as peak ground acceleration is a catalyst that can accelerate phase changes in soft materials. On the other hand, vibration also has a significant impact on slope stability due to its role as a driving factor

A laboratory study by [7], said that the shear strength of soft materials at a laboratory scale has an indirect relationship with the characteristics of their physical properties such as water content and grain size. In the study by Yaya, et. al., [8], the tailings dam safety factor is influenced by the strength material (cohesion and internal friction angle). The analysis was carried out by 2-dimensional FEM modeling. A study by Liew, et.al., [9], stated that the tailings produced by coal mining had a low degree of uniformity. This is confirmed by the seismic refraction research, indicating that the amount of material variety must be considered in the tailings dam's slope stability or embankment.

\section{Tailings Dam Safety Classification}

In general, the safety criteria are regulated in the Decree of the Energy and Mineral Resources Minister No. 1827/K/30/MEM/2018 (Table 1). The safety criteria have captured the coverage of safety factor, landslide probability, and landslide severity [2].

Table 1. Factor of Safety and Probability of Failure

\begin{tabular}{|c|c|c|c|c|}
\hline \multirow{2}{*}{ Slope Type } & \multirow{2}{*}{ Landslide Severity } & \multicolumn{3}{|c|}{ Accepted Criteria } \\
\cline { 3 - 5 } & $\begin{array}{l}\text { Static Safety } \\
\text { Factor (min) }\end{array}$ & $\begin{array}{c}\text { Dynamic Safety } \\
\text { Factor (min) }\end{array}$ & $\begin{array}{c}\text { Probability } \\
\text { of Failure } \\
\text { (max) PF } \\
\text { (FoS } \leq \mathbf{1})\end{array}$ \\
\hline Single Slope & Low until High & 1.1 & None & $25-50 \%$ \\
\hline \multirow{3}{*}{ Interramp Slope } & Low & $1.15-1.2$ & 1.0 & $25 \%$ \\
\cline { 2 - 5 } & Intermediate & 1.2 & 1.0 & $20 \%$ \\
\cline { 2 - 5 } & High & $1.2-1.3$ & 1.1 & $10 \%$ \\
\hline \multirow{3}{*}{ Overall Slope } & Low & $1.2-1.3$ & 1.0 & $15-20 \%$ \\
\cline { 2 - 5 } & Intermediate & 1.3 & 1.05 & $10 \%$ \\
\cline { 2 - 5 } & High & $1.3-1.5$ & 1.1 & $5 \%$ \\
\hline
\end{tabular}


Based on the criteria on Table 1, a tailings dam is an infrastructure that separates from mining slopes and has different characteristics from mining slopes in general. Currently, Indonesia is mostly adopting tailings dam safety criteria based on standards/references from other countries such as Australia [10, 11] and Canada $[12,13]$. The safety criteria for tailings dams are very comprehensive. Therefore, an examination of site-specific investigation is required, with the physical and engineering characteristics of the tailings and base material, geochemical characteristics, water, and environmental conditions, and rheological qualities being the focus of the inquiry [10].

Physical characteristics, engineering, and rheological properties were used to analyze the stability conditions. Specifically, according to $[10,11,12]$ the safety factor for tailings dams must be reviewed from various factors such as seismic activity and loading conditions. The safety criteria suggested by ANCOLD (Australian National Committee of Large Dams) is shown in Table 2.

Table 2. Safety Criteria on Tailings Dam [10]

\begin{tabular}{|l|c|l|}
\hline \multicolumn{1}{|c|}{ Loading Conditon } & Criteria & \multicolumn{1}{c|}{ Shear Strength to be Used } \\
\hline Long-term drained & FOS $\geq 1.5$ & Effective strength \\
\hline $\begin{array}{l}\text { Short-term undrained (Potential } \\
\text { loss of containment) }\end{array}$ & FOS $\geq 1.5$ & Consolidated undrained strength \\
\hline $\begin{array}{l}\text { Short-term undrained (No } \\
\text { potential } \\
\text { loss of containement) }\end{array}$ & FOS $\geq 1.3$ & Consolidated undrained strength \\
\hline Post-seismic & FOS $\geq 1.1$ & Post-seismic shear strength \\
\hline Seismic Deformation & $\leq 50 \% \times$ Design Freeboard & Post-seismic shear strength \\
\hline
\end{tabular}

\section{RESULTS AND DISCUSSION}

\section{Sampling and Testing}

The sampling locations were in two different locations, the in-pit dump and the out-pit dump. Samples were taken in the form of rock and mud. The sampling map can be seen in Figure $\mathbf{3}$ and Figure 4.

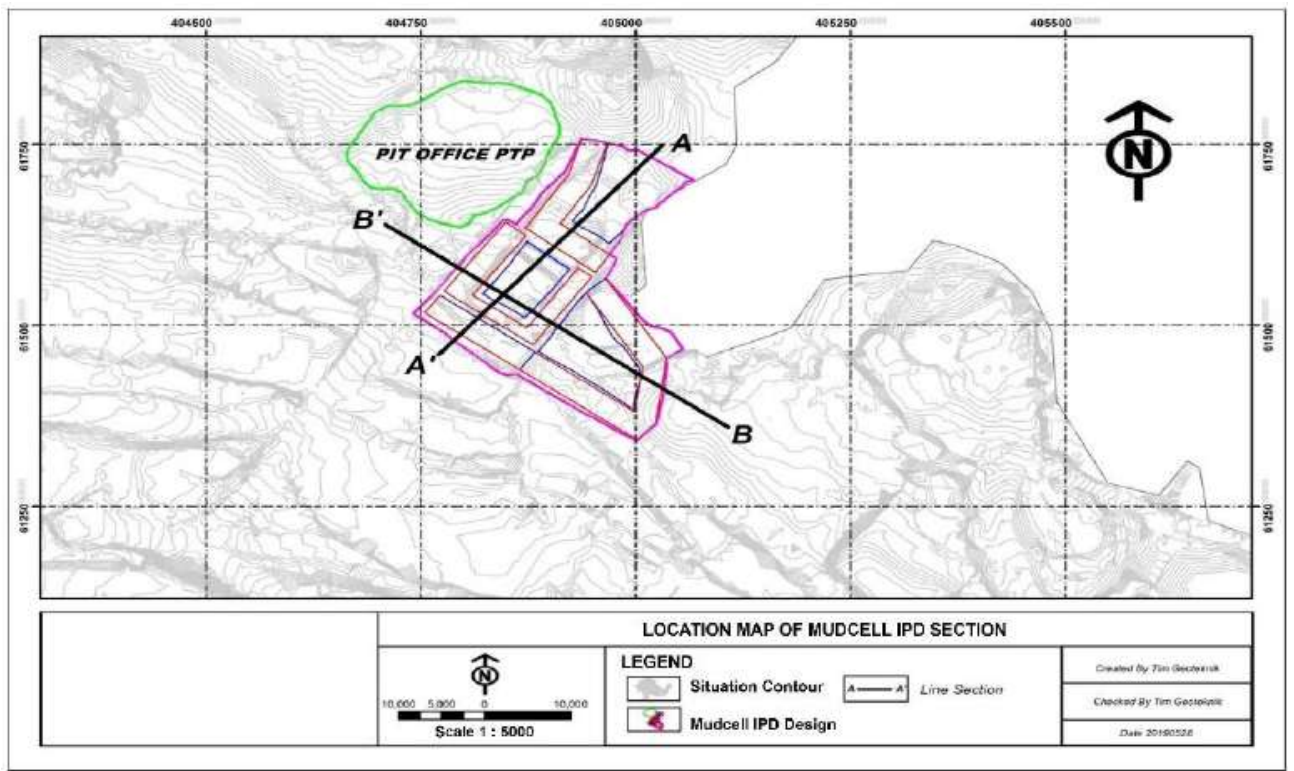

Figure 3. Sampling Locations in Mudcell In-Pit Dump Area 


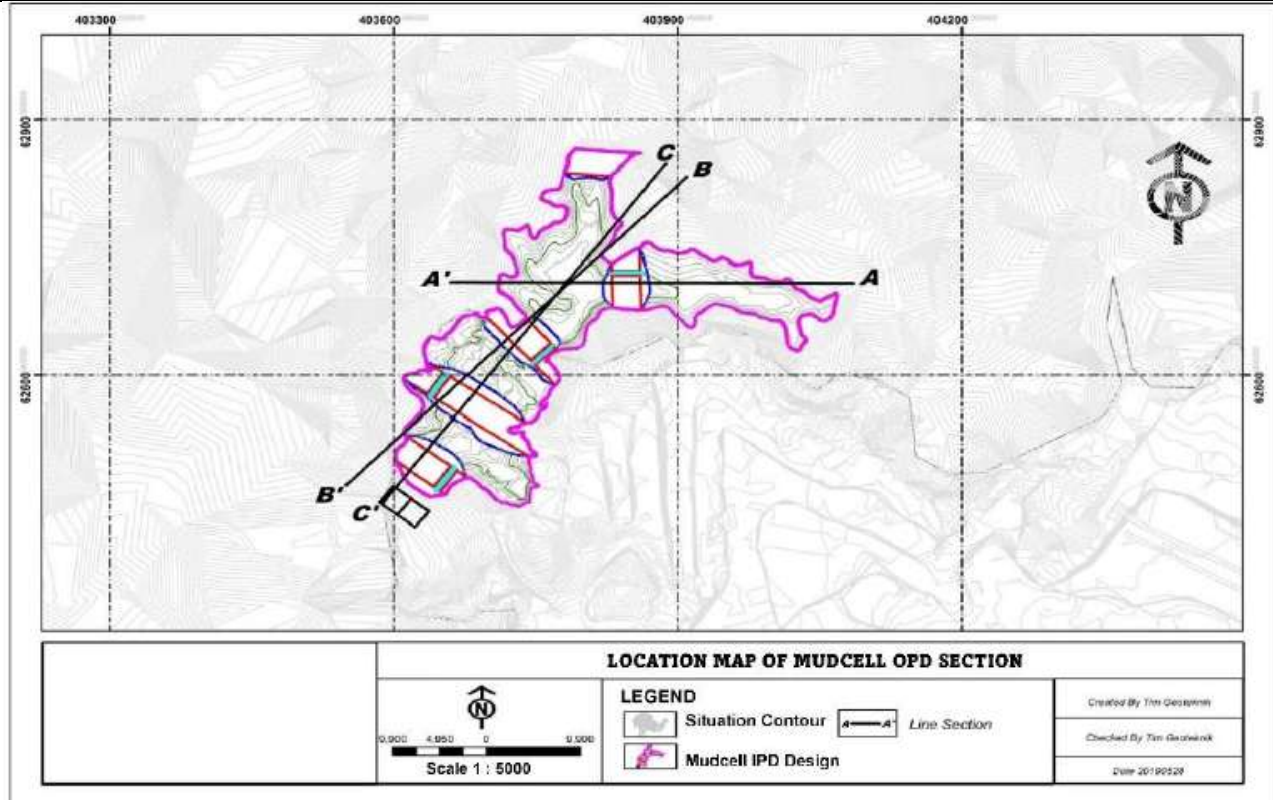

Figure 4. Sampling Locations in Mudcell Out-Pit Dump Area

\section{Processing Data}

The results of sample test were obtained from statistical processing to find the distribution (concentration and trend of distribution patterns) of the right data as the basis for calculating the Probability of Failure software Phase2 v. 8.005. Statistical data processing of the sampling results in this study only refers to the material taken during the site visit. The material properties used in this study can be seen in Table 3.

Table 3. Material Properties Used for Modeling

\begin{tabular}{|c|l|c|c|c|c|c|}
\hline Material & \multicolumn{1}{|c|}{ Parameter } & Mean & SD & Rel Min & Rel Max & Dist. Type \\
\hline \multirow{5}{*}{ Bundwall } & Cohesion $\left(\mathrm{kN} / \mathrm{m}^{2}\right)$ & 18.02 & 4.33 & 5.23 & 7.79 & Gamma \\
\cline { 2 - 7 } & Phi $\left({ }^{\circ}\right)$ & 46.28 & 12.16 & 14.99 & 18.53 & Lognormal \\
\cline { 2 - 7 } & Dry Density $\left(\mathrm{kN} / \mathrm{m}^{3}\right)$ & 14.13 & 1.11 & 1.90 & 1.29 & Normal \\
\cline { 2 - 7 } & Sat Density $\left(\mathrm{kN} / \mathrm{m}^{3}\right)$ & 16.13 & 1.38 & 2.30 & 1.87 & Normal \\
\hline \multirow{5}{*}{ Topsoil } & Cohesion $\left(\mathrm{kN} / \mathrm{m}^{2}\right)$ & 32.77 & 3.29 & 3.50 & 5.42 & Lognormal \\
\cline { 2 - 7 } & Phi $\left({ }^{\circ}\right)$ & 46.31 & 9.33 & 15.02 & 8.24 & Normal \\
\cline { 2 - 7 } & Dry Density $\left(\mathrm{kN} / \mathrm{m}^{3}\right)$ & 10.81 & 0.32 & 0.40 & 0.54 & Lognormal \\
\cline { 2 - 7 } & Sat Density $\left(\mathrm{kN} / \mathrm{m}^{3}\right)$ & 13.74 & 0.29 & 0.27 & 0.51 & Lognormal \\
\hline \multirow{5}{*}{ Base Disposal Disposal } & Cohesion $\left(\mathrm{kN} / \mathrm{m}^{2}\right)$ & 160.28 & 93.37 & 143.78 & 183.72 & Gamma \\
\cline { 2 - 7 } & Phi $\left({ }^{\circ}\right)$ & 10.85 & 3.30 & 5.33 & 5.94 & Normal \\
\cline { 2 - 7 } & Dry Density $\left(\mathrm{kN} / \mathrm{m}^{3}\right)$ & 17.29 & 1.08 & 1.77 & 2.65 & Lognormal \\
\cline { 2 - 7 } & Sat Density $\left(\mathrm{kN} / \mathrm{m}^{3}\right)$ & 20.86 & 0.81 & 1.37 & 2.12 & Lognormal \\
\cline { 2 - 7 } & Cohesion $\left(\mathrm{kN} / \mathrm{m}^{2}\right)$ & 137.96 & 96.22 & 126.96 & 206.04 & Gamma \\
\cline { 2 - 7 } & Phi $\left({ }^{\circ}\right)$ & 21.15 & 4.27 & 8.8 & 10.68 & Normal \\
\cline { 2 - 7 } & Dry Density $\left(\mathrm{kN} / \mathrm{m}^{3}\right)$ & 17.07 & 1.18 & 1.67 & 3.83 & Lognormal \\
\cline { 2 - 7 } & Sat Density $\left(\mathrm{kN} / \mathrm{m}^{3}\right)$ & 20.97 & 0.97 & 1.48 & 3.42 & Lognormal \\
\hline \multirow{5}{*}{ Coal } & Cohesion $\left(\mathrm{kN} / \mathrm{m}^{2}\right)$ & 60.77 & 28.95 & 34.23 & 28.33 & Gamma \\
\cline { 2 - 7 } & Phi $\left({ }^{\circ}\right)$ & 34.52 & 4.22 & 5.38 & 4.76 & Gamma \\
\cline { 2 - 7 } & Dry Density $\left(\mathrm{kN} / \mathrm{m}^{3}\right)$ & 9.26 & 0 & 0 & 0 & Normal \\
\cline { 2 - 7 } & Sat Density $\left(\mathrm{kN} / \mathrm{m}^{3}\right)$ & 12.77 & 0.75 & 0.60 & 1.07 & Gamma \\
\hline
\end{tabular}

\section{Mudcell In-Pit Dump Area}

The modeling of the in-pit dump mudcell area used the following approaches. 
a. The modeling sections used are sections $A$ and $B$.

b. The modeling was carried out in 4 conditions with the following detail conditions:

1) Fluid storage without using an impermeable layer.

2) The fluid reservoir uses an impermeable layer with a thickness of $0.35 \mathrm{~m}$. The impermeable layer is assumed to be a material such as topsoil.

3) The fluid reservoir has been filled by the embankment so that it becomes a 1:4 mudco.

4) The fluid reservoir has been filled by the embankment so that it becomes a 1:2 mudco.

c. The fluid properties in conditions 1 and 2 use the properties of the water/mud laboratory test sample.

d. The bundwall in dry condition.

e. The seismic factor used is $0.05 \mathrm{~g}$.

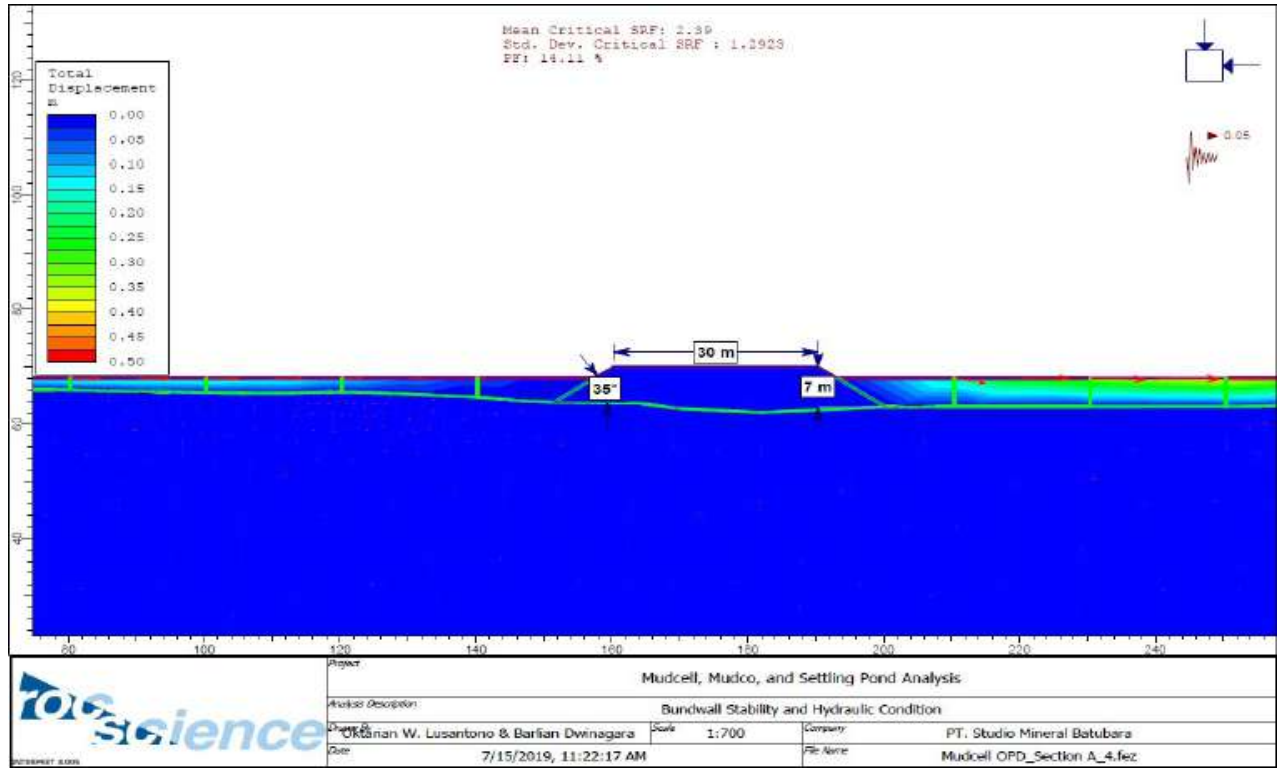

Figure 5. Section A Condition 4 Modeling (Mudcell InpitAre)

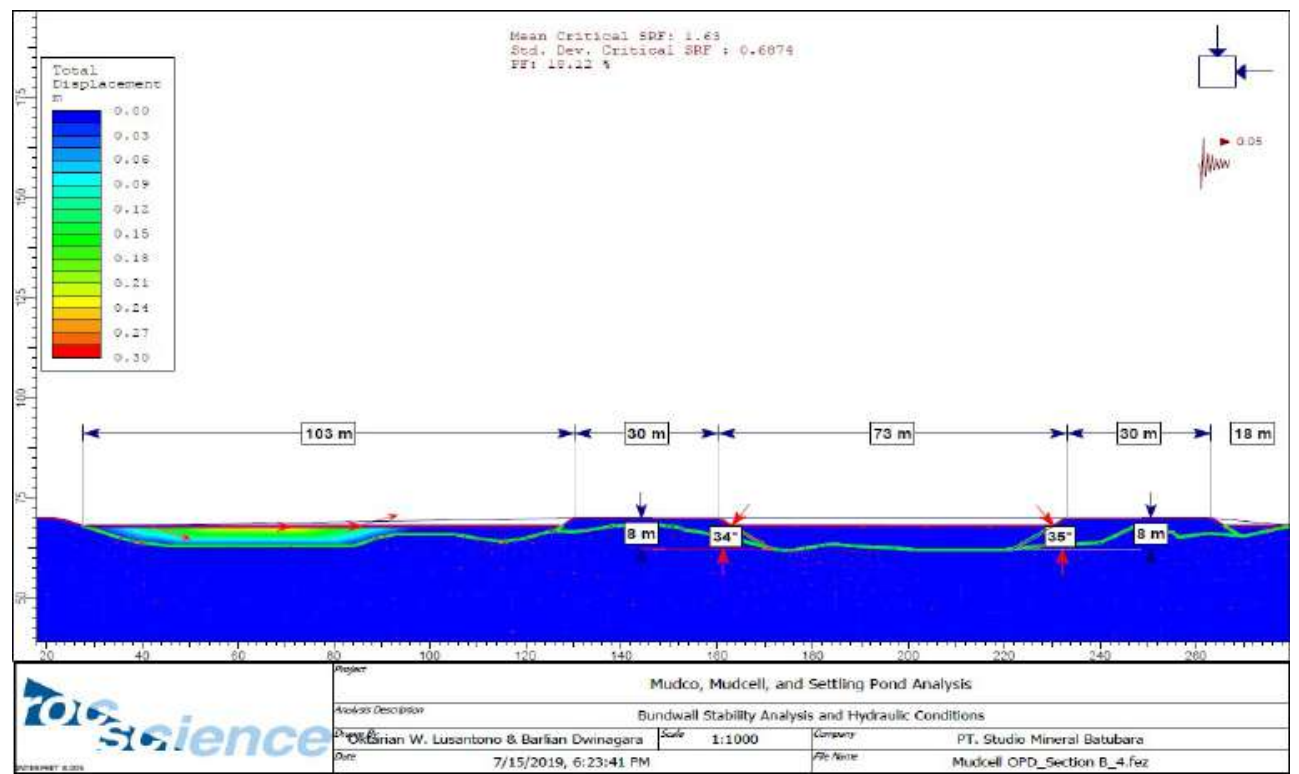

Figure 6. Section B Condition 4 Modeling (Mudcell InpitAre) 
Table 4. Meanwhile, some examples of the geotechnical modeling are shown in Figure 5 and Figure 6.

Table 4. Recapitulation of FoS and PF in Mudcell In-pit Dump Area

\begin{tabular}{|c|c|c|c|}
\hline Section & Condition & $\begin{array}{c}\text { FoS Mean } \\
\text { (SRF Mean) }\end{array}$ & $\begin{array}{c}\text { Probability } \\
\text { Failure (\%) }\end{array}$ \\
\hline \multirow{4}{*}{$\mathrm{A}$} & 1 & 5.02 & 1.16 \\
\cline { 2 - 4 } & 2 & 2.34 & 11.28 \\
\cline { 2 - 4 } & 3 & 7.24 & 1.09 \\
\cline { 2 - 4 } & 4 & 2.75 & 0.06 \\
\hline \multirow{4}{*}{ B } & 1 & 8.18 & 0.88 \\
\cline { 2 - 4 } & 2 & 7.96 & 0.62 \\
\cline { 2 - 4 } & 3 & 8.47 & 0.61 \\
\cline { 2 - 4 } & 4 & 4.41 & 3.39 \\
\hline
\end{tabular}

From the results of geotechnical modeling, it is known that the bundwall conditions of the in-pit dump mudcell area are included in the safe category (FoS $>1.1$ and PF $<25 \%$ ). Stress-strain analysis is expressed by the estimated total displacement. From the modeling results, section A has a larger total displacement than section B. This is possible because the position of section A leads directly to the highwal (Figure 3). This also results in the direction of material displacement leading to the highwall. The recommended total displacement refers to the threshold warning monitoring system. For the mudcell in-pit dump area assuming the age of the bundwall is 1 month, then the total accepted

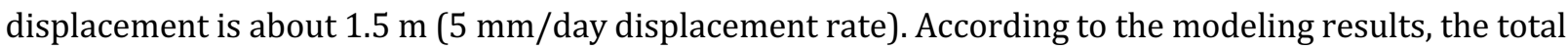
displacement has exceeded the allowable total displacement $(>1.5 \mathrm{~m})$. Therefore, the condition of the bundwall needs to be monitored and conditioning if it has exceeded the allowable displacement rate by the installed monitoring system.

Based on the total displacement value, condition 4 has the largest total displacement in section A. Therefore, the recommended solid material recommendation for filling the mudcell compartment is a ratio of 1:4 (1 mud and 4 solids). This is because the 1:4 mudco material has a large enough cohesion value (same as the bundwall) so that it can hold the load of the material.

In addition, according to hydraulic study, the mudcell bundwall has a permeability coefficient of $3.20 \mathrm{x}$ $10^{-9} \mathrm{~m} / \mathrm{s}$. The bundwall material condition is included in the material with low - extremely low permeability. As a result, bundwall can be divided into impermeable and permeable materials. By using a steady-state approach, water from the mudcell compartment can flow from the left to the right due to the difference in water level in compartments 1 and 2 .

\section{Mudcell Out-Pit Dump Area}

The modeling of the out-pit dump mudcell area used the following approaches.

a. The modeling sections used are sections A and B.

b. The modeling was carried out in 4 conditions with the following detail conditions:

1) Fluid storage without using an impermeable layer.

2) The fluid reservoir uses an impermeable layer with a thickness of $0.35 \mathrm{~m}$. The impermeable layer is assumed as topsoil material.

3) The fluid reservoir has been filled by the embankment so that it becomes a 1:4 mudco. 
4) The fluid reservoir has been filled by the embankment so that it becomes a 1:2 mudco.

c. The fluid properties in conditions 1 and 2 use the properties of the water/mud laboratory test sample.

d. The bundwall in dry condition.

e. The seismic factor used is $0.05 \mathrm{~g}$.

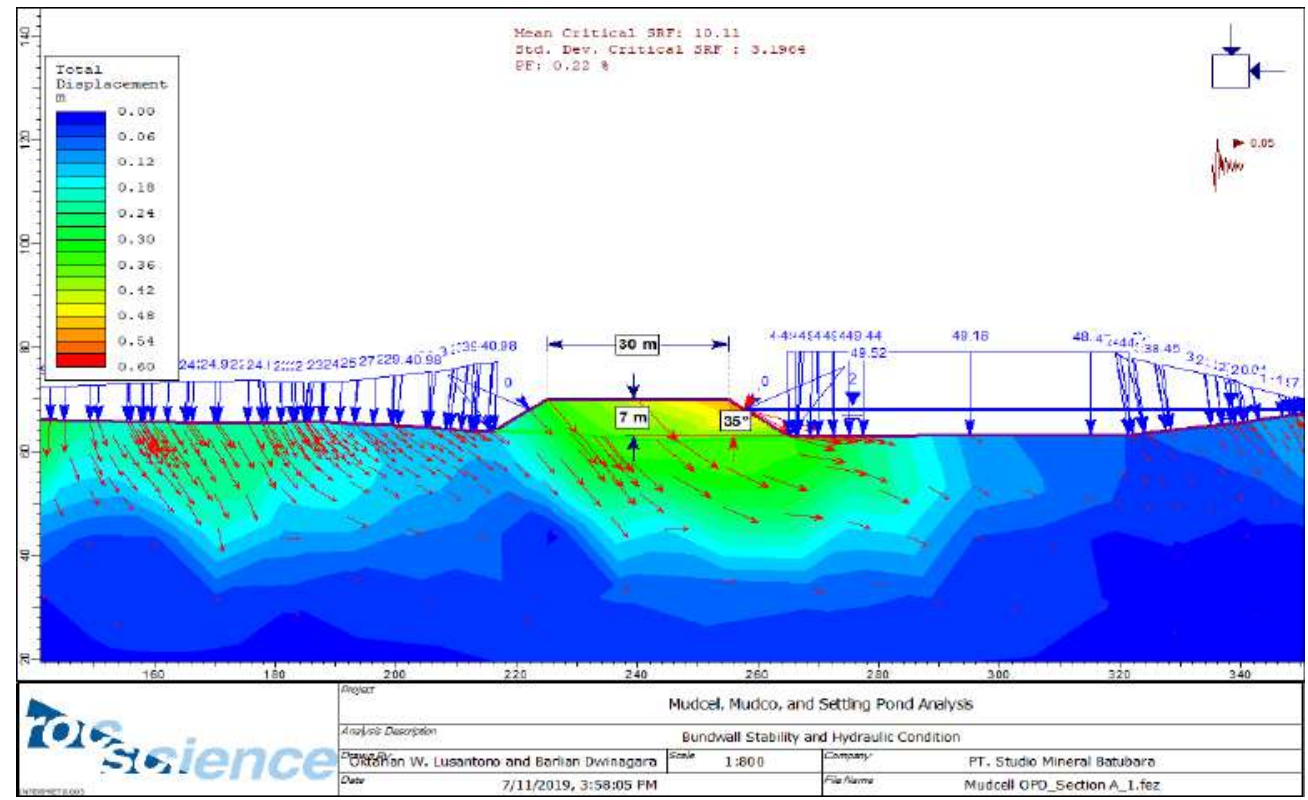

Figure 7. Section A Condition 1 Modeling (Mudcell OutpitAre)

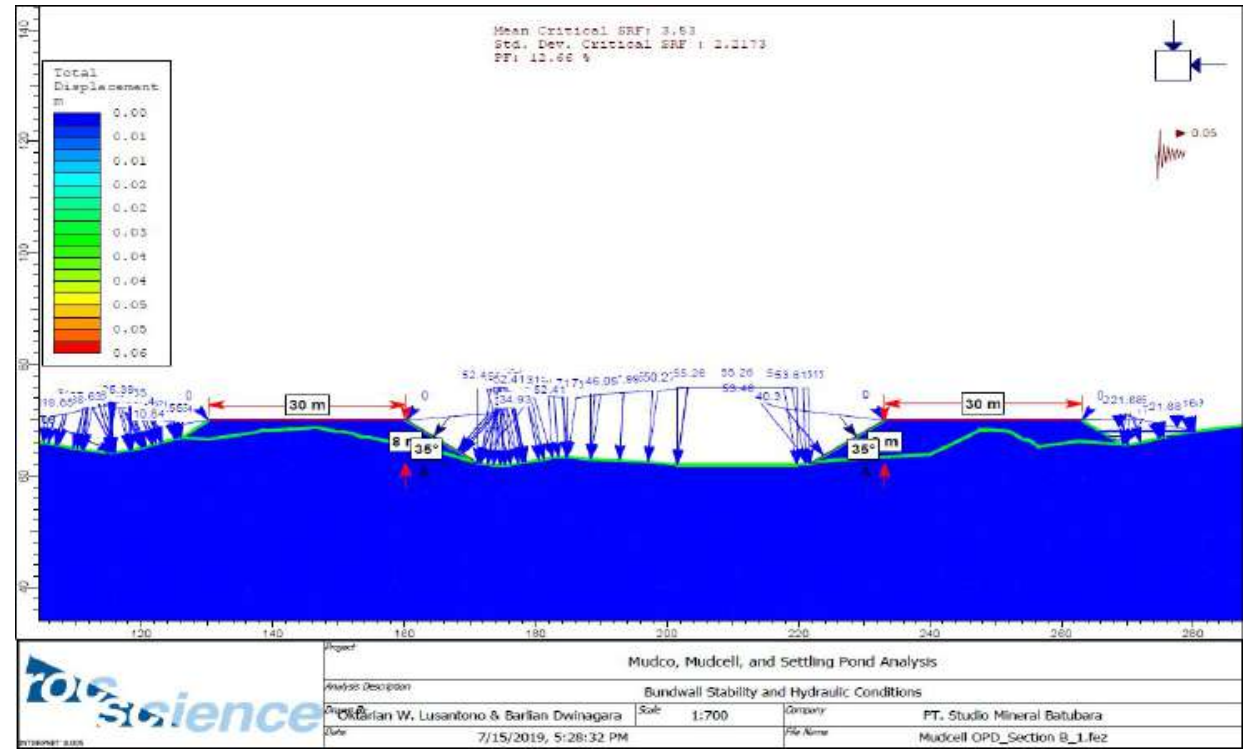

Figure 8. Section B Condition 1 Modeling (Mudcell OutpitAre)

The recapitulation result of FoS and PF can be seen in Table 5. Meanwhile, some examples of the geotechnical modeling are shown in Figure 7 and Figure 8.

Table 5. Recapitulation of FoS and PF in Mudcell Out-pit Dump Area

\begin{tabular}{|l|l|c|c|}
\hline Section & Condition & $\begin{array}{c}\text { FoS Mean } \\
\text { (SRF Mean) }\end{array}$ & $\begin{array}{c}\text { Probability } \\
\text { Failure (\%) }\end{array}$ \\
\hline
\end{tabular}




\begin{tabular}{|c|c|c|c|}
\hline \multirow{4}{*}{$\mathrm{A}$} & 1 & 10.11 & 0.22 \\
\cline { 2 - 4 } & 2 & 3.46 & 0 \\
\cline { 2 - 4 } & 3 & 3.61 & 4.55 \\
\cline { 2 - 4 } & 4 & 2.39 & 14.11 \\
\hline \multirow{4}{*}{$B$} & 1 & 3.53 & 12.66 \\
\cline { 2 - 4 } & 2 & 3.55 & 11.98 \\
\cline { 2 - 4 } & 3 & 3.52 & 12.18 \\
\cline { 2 - 4 } & 4 & 1.62 & 18.12 \\
\hline
\end{tabular}

From the results of geotechnical modeling, it is known that the average condition of the out-pit dump mudcel bundwall area is included in the safe category ( $\mathrm{FoS}>1.1$ and $\mathrm{PF}<25 \%$ ). Stress-strain analysis is expressed by the estimated total displacement. Based on the analysis results, the largest total material displacement occurred in section A condition 1 (maximum $0.6 \mathrm{~m}$ ).

The bearing capacity of the base material in the Mudcell out-pit dump area can be seen in Table 6 . The carrying capacity of the base material for the embankment ranges from $5.06-7.11 \mathrm{~kg} / \mathrm{cm}^{2}(496.27-$ $697.04 \mathrm{kN} / \mathrm{m}^{2}$ ) from the calculation results. Formula (1) - (4). The load of the embankment material (bundwall) in section A can be calculated as follows:

The bearing capacity value of the base material in mudcell out-pit dump area can be seen in Table 6 . The bearing capacity of the embankment base material ranges from $5.06-7.11 \mathrm{~kg} / \mathrm{cm}^{2}(496.27-697.04$ $\mathrm{kN} / \mathrm{m}^{2}$ ) from the formula calculation results (1) - (4). The load of the embankment material (bundwall) in section A can be calculated as follows:

- Average density $\quad=14,13 \mathrm{kN} / \mathrm{m}^{3}$

- Bundwall volume $=42.962 \mathrm{~m}^{3}$

- Bundwall area $\quad=7.999,31 \mathrm{~m}^{2}$

- Load of bundwall area $\quad=14,13 \mathrm{kN} / \mathrm{m}^{3} \times 42.962 \mathrm{~m}^{3}$

$$
=606,967 \mathrm{kN}
$$

- Bundwall pressure $=606.967 \mathrm{kN}: 7.999,31 \mathrm{~m}^{2}$

$$
=14,12 \mathrm{kN} / \mathrm{m}^{2}
$$

\begin{tabular}{|c|c|c|c|c|c|}
\hline Material & Cohesion $\left(\mathrm{kN} / \mathrm{m}^{2}\right)$ & Approach Formula & $\begin{array}{l}\text { CBR } \\
\text { (\%) }\end{array}$ & $\begin{array}{c}\text { DDT } \\
\left(\mathrm{kg} / \mathrm{cm}^{2}\right)\end{array}$ & $\begin{array}{c}\text { DDT } \\
\left(\mathrm{kN} / \mathrm{m}^{2}\right)\end{array}$ \\
\hline \multirow{3}{*}{ Base Disposal } & \multirow{3}{*}{137,96} & Brown (1987) & 17,69 & 7,11 & 697,04 \\
\hline & & & 11,99 & 6,37 & 624,96 \\
\hline & & Black (1979) & 5,99 & 5,06 & 496,27 \\
\hline
\end{tabular}

Table 6. Bearing Capacity Value of Mudcell Out-pit Dump Basic Material

The direction of total material displacement in section A condition 1 mostly moves downwards to the settlement. It can be seen in Figure 7 that the total displacement vector mostly occurs at the bundwall location and the location of the fluid reservoir, the vector stops at the embankment base material. It is indicated that the base material of the out-pit dump mudcell area still able to hold the pressure caused by the bundwall and mudcell compartment. Based on the carrying capacity analysis, the out-pit dump mudcell base material has a higher bearing capacity value than the bundwall load. Considering that there are no displacement criteria in the out-pit dump mudcell area, it is necessary to monitor the area as a verification of the modeling results in the form of monitoring the displacement and material's bearing capacity.

Based on the analysis of hydraulic conditions, the mudcell bundwall has a permeability coefficient of 4.3 $\mathrm{x} 10^{-10} \mathrm{~m} / \mathrm{s}$. The condition of the bundwall material is included in the material with low - very low permeability. Therefore, bundwall can be categorized into impermeable materials. By using the steadystate approach, water from the mudcell compartment does not flow towards the bundwall. 


\section{CONCLUSIONS}

Based on bund wall stability analysis and hydraulic condition, the conclusions are:

1. Mudcell in-pit dump area has a total displacement criterion that exceeds the applied threshold warning system. Monitoring and conditioning are needed to be done in the mudcell in-pit dump area if it exceeds the criteria for the landslide warning system.

2. A monitoring system is needed in the mudcell out-pit dump area as a form of modeling results verification.

3. The flow direction in each area depends on the compartment elevation and the height of the water table (mud). Bundwall material is considered a low permeability material $\left(\mathrm{k} \leq 7,87 \times 10^{-9} \mathrm{~m} / \mathrm{s}\right)$. Thus, it is assumed that it cannot release the water from existing mud compartments.

\section{REFERENCES}

[1] G. M. Mudd, "Mining and Water Resources," in Encyclopedia of the World's Biomes, Elsevier, 2020, pp. 45-54.

[2] D. C. Wyllie and C. W. Mah, Rock Slope Engineering: Civil and Mining, 4th ed., New York: Taylor \& Francis, 2004.

[3] U.S. Federal Highway Administration, Rock Slopes: Design, Excavation, Stabilization, Georgetown: U.S. Department of Transportation, 1989.

[4] K. Terzaghi, R. B. Peck and G. Mesri, Soil Mechanics in Engineering Practice, New york: John Wiley \& Sons, Inc., 1996.

[5] S. L. Kramer, Geotechnical Earthquake Engineering, New Jersey: Prentice-Hall Inc., 1996.

[6] B. M. Das, Principles of Geotechnical Engineering, Stamford: Cengage Learning, 2006.

[7] A. Saengthongthrip and R. Nuntasarn, "Drained shear strength parameters of compacted Khon Kaen Loess by direct shear test," International Journal of GEOMATE, vol. 16, no. 57, pp. 28-34, 2019.

[8] C. Yaya, B. Tikou and C. LiZhen, "Numerical analysis and geophysical monitoring for stability assessment of the Northwest tailings dam at Westwood Mine," International Journal of Mining Science and Technology, vol. 27, pp. 701-710, 2017.

[9] M. Liew, M. Xiao, S. Liu and S. Rudenko, "In situ seismic investigation for evaluating geotechnical properties and liquefaction potential of fine coal tailings," Journal Geotechnics and Geoenvironment, vol. 146, no. 5, 2020.

[10] ANCOLD, Guidelines on Tailings Dams: Planning, Design, Construction, Operation and Closure, ANCOLD Inc., 2012.

[11] ANCOLD, Guidelines on Talings Dams - Planning, Design, Construction, Operation, and Closure Revision 1, Sydney: ANCOLD, 2019.

[12] APEGBC, Site Characterization For Dam Foundations in BC, Vancouver: APEGBC, 2016.

[13] The Mining Association of Canada, A Guide to the Management of Tailings Facilities, The Mining Association of Canada, 2019. 